\title{
Colóquios filosóficos como meio de melhoria na aprendizagem em Filosofia para os alunos do Ensino Médio
}

\author{
Ana Cristina Aureliano \\ Universidad de Santiago de Chile (Chile)
}

\section{Resumo}

Este trabalho busca oferecer mediação pedagógica aos alunos do $9^{\circ}$ ano de um colégio da rede particular, a fim de melhorar a apreensão do conceito em relação à política, tais como: conhecimento, ética e moral, nas primeiras séries do Ensino Médio na disciplina de filosofia. Para atender a este objetivo, foi elaborado como estratégia didática os Colóquios Filosóficos, por se tratar de um meio de desenvolver temas pré-definidos, com exposições, debates e busca de tomada de decisões. Foi realizado uma sondagem inicial para saber qual o conhecimento prévio dos alunos do $9^{\circ}$ ano sobre política, numa perspectiva filosófica, o planejamento dos colóquios com os palestrantes convidados, a realização dos colóquios, o monitoramento e a avaliação final. Trazendo como resultados o interesse dos alunos para participar dos colóquios, discussões e questionamentos, dando resposta a capacidade de apreensão de conteúdos sistemáticos da grade curricular do Ensino Médio de forma prazerosa e eficaz.

Palavras-chave: Ensino de filosofia. Aprendizagem. Inovação educacional. Colóquios.

\section{Philosophical collocks as a means of improving learning in Philosophy for students in the first series of High School}

\begin{abstract}
This work seeks to offer pedagogical mediation to 9th grade students at a private school, in order to improve the understanding of the concept in relation to politics, such as: knowledge, ethics and morals, in the first grades of high school in the discipline of philosophy. To meet this objective, the Philosophical Colloquiums were developed as a didactic strategy, as it is a means of developing pre-defined themes, with exhibitions, debates and the search for decision-making. An initial survey was carried out to find out what the 9th year students' previous knowledge of politics, from a philosophical perspective, the planning of the colloquia with the invited speakers, the conduct of the colloquia, the monitoring and the final evaluation. Bringing as a result the interest of students to participate in colloquia, discussions and questions, giving an answer to the ability to apprehend systematic content of the curriculum of high school in a pleasant and effective way. Keywords: Philosophy teaching. Learning. Educational innovation. Colloquia.
\end{abstract}




\section{Colocaciones filosóficas como medio de mejorar el aprendizaje en Filosofía para estudiantes de la primera serie de Escuela Secundaria}

\section{Resumen}

Este trabajo busca ofrecer mediación pedagógica a estudiantes de noveno grado en una escuela privada, con el fin de mejorar la comprensión del concepto en relación con la política, como: conocimiento, ética y moral, en los primeros grados de secundaria en la disciplina de filosofía. Para cumplir este objetivo, los coloquios filosóficos se desarrollaron como una estrategia didáctica, ya que es un medio para desarrollar temas predefinidos, con exposiciones, debates y la búsqueda de toma de decisiones. Desde una perspectiva filosófica, la planificación de los coloquios con los oradores invitados, la realización de los coloquios, el seguimiento y la evaluación final, se realizó una encuesta inicial para averiguar cuál era el conocimiento previo de los estudiantes de noveno año sobre política. Trayendo como resultado el interés de los estudiantes para participar en coloquios, discusiones y preguntas, dando una respuesta a la capacidad de comprender el contenido sistemático del plan de estudios de la escuela secundaria de una manera agradable y efectiva.

Palabras claves: Enseñanza de la filosofía. Aprendizaje. Innovación educativa. Coloquios.

\section{Introdução}

propósito deste texto é apresentar um projeto de inovação realizado na disciplina de Filosofia num colégio da rede particular de ensino. Neste foram levantados problemas e analisados em vista de aplicar uma proposta de melhoramento no nível educacional do Ensino Fundamental para o Ensino Médio.

$\bigcirc$ projeto surgiu da dificuldade apresentada pelos alunos da série em questão, e representada numericamente principalmente com as notas do primeiro trimestre. Com esta constatação foi percebido um problema a ser trabalhado e pretensamente superado que é: a dificuldade na apreensão de conceitos humanísticos em relação à política, tais como: o conhecimento, ética e moral, na primeira série do Ensino Médio.

Já no final do século XIX e início do século XX, vive-se uma crise do ideal de um sujeito autônomo, abrindo-se assim um espaço para as psicologias. A cultura até então regida pelo tribunal epistemológico sede lugar a uma cultura em que a ética assume uma posição central. Se o sujeito não se questiona criticamente a respeito do seu modo de agir, sobre os valores e representações que dão sentido ao seu modo de ser e de viver, corre o risco 
de perder a consciência de si mesmo e do sentido do seu ser. Assim, conforme Gambim (2000, p. 16), "[...] a Filosofia é necessária, não apenas como uma exigência teórica especulativa, mas como uma exigência interna da própria vida humana, que se interroga e busca legitimar-se e encontrar suas "razões de ser" $^{\prime \prime \prime}$.

A filosofia deve fazer parte do currículo escolar, não pela resposta imediata que possa dar aos problemas, mas sim por causa dos próprios problemas, isto é, porque o seu estudo amplia as nossas ideias acerca daquilo que é possível e desejável concretizar.

O estudo da filosofia, enriquece a imaginação intelectual da pessoa, questiona a arrogância dogmática. Sobretudo, porque engrandece o espírito, tornando-o capaz de perceber a multiplicidade de pontos de vista e articulações possíveis entre os mesmos, ajudando-o a compreender que o caminho é um processo, que pode ser para cima e para frente (ESQUISANI 2001, p. 19).

Os Parâmetros Curriculares Nacionais para o Ensino Fundamental (PCNEF), publicados em 1998, preveem a adoção de temas transversais nesse nível de ensino, notadamente nas áreas de ética e cidadania. Também os Parâmetros Curriculares Nacionais para o Ensino Médio (PCNEM), de 1999, preveem que conteúdos de filosofia devam ser trabalhados na forma de temas transversais, embora, nestes, a filosofia apareça como uma disciplina da área de "Ciências Humanas e Suas Tecnologias". Estas disposições especificam o que já as Leis de Diretrizes e Bases-LDB havia determinado (Seção IV, artigo 36, parágrafo $1 \%$ : "que os estudantes, ao final do ensino médio, demonstrem "dominar os conhecimentos de filosofia e de sociologia necessários ao exercício da cidadania".

Assim, a Filosofia visa apresentar uma visão globalizante, interdisciplinar e mesmo transdisciplinar, auxiliando o educando a lançar outro olhar sobre o mundo e a transformar a experiência vivida em uma experiência compreendida (LIMA, 2018, p. 18).

Este projeto de inovação educativa nos faz refletir o quanto se está retirando dos alunos a possibilidade de ampliar seus conhecimentos, talvez por julgá-los imaturos para tal conhecimento e por isto, empobrece e atrofia a capacidade de conhecimento dos alunos. 
Platão já se referia à educação da infância, afirmando que essa se iniciava ainda no útero materno... Para Platão, a educação tem um fim último, a formação moral do homem para que esse venha a exercer com justiça o seu papel dentro do Estado (LUZURIAGA apud CIRINO, 2014, p. 1391.

Observa-se que a imagem da criança na literatura grega também é ressaltada, como afirma Kohan (2008, p. 12), que Crítias testemunha que a infância é, para os gregos, um período extraordinário para o aprendizado: "[...] é comum dizer que o que se aprende sendo criança fica de modo admirável na memória".

Lipman (apud Lorieri 2014 , p. 239) diz: "Talvez em nenhum outro lugar a filosofia seja mais bem-vinda do que no início da educação escolar, até agora um deserto de oportunidades perdidas." Pois a capacidade de questionar, e de querer saber a razão de todas as coisas é própria da criança e então, por que só disponibilizar o contato e conhecimentos da disciplina de filosofia apenas no Ensino Médio onde os adolescentes já estão com uma carga de conhecimentos para dar conta no Enem?

A apropriação dos saberes filosóficos, quanto mais na tenra idade se é oferecida, mas se oportuniza na construção da investigação, do saber o porquê e não apenas aceitar o que é oferecido sem um questionamento. Não se constrói o homem crítico que está em tantas propostas educativas, no Ensino Médio. $\bigcirc$ homem crítico se constrói desde a infância.

Várias questões do pensamento já são colocadas para as crianças da educação infantil pela primeira vez. $\bigcirc$ estado de espanto, maravilhamento ou dúvida que elas podem experienciar é semelhante ao de filósofos calejados em seu treino metódico de fazer reflexão e crítica filosóficas. Isso já bastaria para se considerar válido o ensino de filosofia às crianças da educação infantil (CUNHA apud LORIERI, 2014, p. 108).

A sociedade contemporânea encontra-se em meio a uma anestesia reflexiva sobre ela mesma. A nossa cultura idealiza o sujeito acerca de como ele deve ser, viver, desejar e pensar, impossibilitando a totalidade de conhecimentos e pensamentos que podem ser alcançados. Enquanto disciplina, a Filosofia se propõe a educar o ato de pensar, originando novas formas de ver 
o mundo. Ela permite essa atitude de interrogar-se, à medida que se dirige ao próprio pensamento, se efetivando enquanto reflexão.

ensino da filosofia no âmbito escolar é uma possibilidade para que seja proporcionada um espaço de aprendizagem mais prazeroso, significativo, que desafiem os alunos a pensar, conhecer, criticar, informar para que atuem no mundo em que vivem com sabedoria e justiça e, assim, transformem o hoje e o amanhã em dias cada vez melhores.

A filosofia amplia as relações entre a educação e a sociedade, unindo o saber e o fazer que são elementos essenciais na construção do social. Aí está a razão para a filosofia permanecer nos currículos escolares, pois subsidia o aprimoramento da reflexão filosófica própria de cada ser humano.

Porém a disciplina de filosofia só é obrigatória no último nível da educação básica. Deixando assim os demais níveis de escolaridade carente deste subsídio reflexivo.

[...] a filosofia deve ser considerada uma disciplina obrigatória no ensino médio, com seus textos próprios que exprimam sua história e identidade, visto que essa condição é indispensável para que ela contribua no debate com as outras disciplinas e nos projetos transversais (SILVA apud BRASIL, 2019 , p. 4).

Segundo Kohan (apud LIMA, 2018, p. 17), "[...] o programa pioneiro de Mathew Lipman de Filosofia para Criança, chegou no Brasil em 1984, por intermédio da professora Catherine Young Silva". Sua proposta foi dotada no Brasil por algumas escolas em sua maioria particulares.

Apesar da sua regulamentação está apontando apenas para o Ensino Médio, os Parâmetros Curriculares Nacionais para o Ensino Fundamental (PCNEF), publicados em 1998, preveem a adoção de temas transversais nesse nível de ensino, notadamente nas áreas de ética e cidadania, o que possibilita a inserção da disciplina nos demais níveis. Principalmente se partirmos da filosofia argumentativa a partir de atitudes transdisciplinares com estudo de textos e debates em outras áreas do conhecimento.

Como este projeto de inovação tem a intenção de contribuir para uma aprendizagem mais significativa para os alunos do $9^{\circ}$ ano do Ensino Fundamental na disciplina de filosofia através de colóquios, faz-se necessário 
aqui trazer um pouco sobre aprendizagem e a possibilidade de ela acontecer por meio de colóquios.

A aprendizagem é caracterizada pelo ato de aprender, e não uma possibilidade exclusiva na escola, se aprende de várias formas e em vários contextos. Mas como o projeto acontece num espaço escolar, trataremos da aprendizagem escolar por seu caráter sistemático e intencional, e pela organização das atividades dirigidas e avaliadas.

diferencial desde projeto não é apenas antecipar alguns conteúdos filosóficos que são pré-requisitos para a série seguinte, mas trazer estes conceitos de forma prazerosa e sem a cobrança de uma nota ou que os alunos devem dar uma resposta a estes conceitos, mas a percepção destes conceitos no dia a dia de cada um, bem como, em outras disciplinas.

$\bigcirc$ formato de colóquios para implementação deste projeto foi intencional por se tratar de uma abordagem de trabalho em que se apresenta, discute, busca soluções de temas antecipadamente definidos, não correndo o risco de fugir da proposta inicial. Flechsing; Schiefelbein (2003, p. 72), afirma que "O aluno adquire conhecimento - especialmente sobre experiências pessoais, avaliações e propostas - através da troca de informações e opiniões com os outros participantes."

Com o professor de filosofia do colégio, foram levantados os conteúdos da grade curricular da $1^{a}$ série do Ensino Médio que os alunos apresentaram dificuldade, a partir dessas informações foram identificados quais os conceitos filosóficos significativos para a aprendizagem seriam trabalhados na estratégia dos Colóquios Filosóficos.

\section{Metodologia}

As turmas dos anos finais do Ensino Fundamental foram escolhidas para o desenvolvimento do projeto de inovação, por se tratar dos alunos que irão ter posteriormente o contato com a disciplina de Filosofia, podendo assim, dar resposta se com a antecipação de conteúdos pré-requisitos ou até mesmo, a ampliação da discussão de temas pertinentes, contribuíram para um melhor desempenho destes alunos quando colocados para o estudo da nova disciplina. 
A proposta de Colóquios Filosóficos onde os alunos têm contato com temas que fazem parte do seu cotidiano, mas que não são discutidos e pensados de forma sistemática, possibilita uma aproximação com a disciplina de Filosofia de forma prazerosa e sem estabelecer um preconceito. Pois o ato de pensar filosoficamente é estabelecido com o uso de habilidades de pensamento, como explicar, dar definições, reformular, criar conceitos e não somente repeti-los.

Neste caminho, foram realizados quatro colóquios com temas que ajudou os alunos, ora do $9^{\circ}$ ano do Ensino Fundamental, numa melhor compreensão e apreensão dos conteúdos didáticos abordados na $1^{a}$ série do Ensino Médio. Estes colóquios foram ministrados por mestres e doutores convidados para tratar dos temas relacionados a política, visto que este é o conteúdo do primeiro trimestre de filosofia da $1^{a}$ série do Ensino Médio, etapa que foi considerada para o diagnóstico das dificuldades de aprendizagem dos alunos.

Com a aplicação de alguns instrumentos para coleta de informações como: a) análise documental, que fotografou a dificuldade que os alunos da $1^{a}$ série do Ensino Médio tem com a disciplina de filosofia; b) análise FODA', ressaltou que com o estrito cumprimento da lei quanto a carga horária reduzida diante do arcabouço de conteúdos a serem trabalhados e quanto a presença da disciplina apenas no Ensino Médio, dificulta para um melhor conhecimento dos conceitos a serem apreendidos pelos alunos; e c) entrevista estruturada, que endoçou os apectos apresentados nos dois outros instrumentos realizados anteriormente.

Mediante este quadro, foi pensado como estratégia para a proposta de inovação a promoção de Colóquios Filosóficos para os alunos do $9^{\circ}$ ano do Ensino Fundamental, possibilitando um contato antecipado de alguns conteúdos significativos para aprendizagem da disciplina de filosofia no primeiro trimestre do ano posterior, quando estes alunos estiverem na $1^{a}$ série do Ensino Médio. Já que foi detectado a dificuldade dos alunos com a disciplina principalmente neste período.

Foram convidados para a execução da inovação, profissionais envolvidos nesse contexto como mestres e doutores em filosofia, que em quatro colóquios temáticos abordaram sobre o conhecimento, a ética e a moral. Conhecimentos e conceitos importantes para uma melhor apreensão do ensino da filosofia na $1^{a}$ série do Ensino Médio. Foram selecionados trechos de filmes 
como: A experiência (discute a relação entre o poder adquirido em relação aos que não possuem esse poder) e $\bigcirc$ jardineiro fiel (discute a relação ética das empresas farmacêuticas em usarem pessoas como cobaias para seus medicamentos), de forma a sensibilizá-los; charges, música: "Coisas que eu sei" de Danni Carlos.

Com a intenção de trazer uma temática filosófica em conformidade com as orientações do Congresso Internacional de Locarno (1997), quando explicita:

[...] a necessidade de haver educadores animados por uma atitude transdisciplinar que considere o diálogo arte/ciência como um dos maiores "[...] eixos da nova educação, visando à reunificação das duas culturas artificialmente antagônicas: a cultura científica e a cultura artística, [...] mediante uma nova cultura multidimensional, [...] (SILVA, apud CONGRESSO DE LOCARNO, 2019, p. 21).

Assim, observando cada atitude e implicação do mesmo em suas vidas, para que tenham atitudes diferentes dos habituais. Com o intuito de transformar não apenas a nota no primeiro trimestre do ano seguinte, mas tam-

8 bém o ambiente, a forma de olhar o mundo e o futuro de cada um, para que posteriormente tenhamos uma sociedade menos alienada.

As atividades propostas para desenvolver o projeto: Colóquios Filosóficos estão representadas no quadro abaixo, apresentando o objetivo de cada atividade.

\section{Tabela 1}

\section{Atividades desenvolvidas na inovação}

\begin{tabular}{l}
\multicolumn{1}{c|}{ Atividades } \\
\hline $\begin{array}{l}\text { Atividade 1: Apresentar a proposta e solicitar a aplicação do projeto a Equipe } \\
\text { Diretiva do colégio. }\end{array}$ \\
\hline Atividade 2: Apresentar a coordenação a proposta dos Colóquios Filosóficos. \\
\hline $\begin{array}{l}\text { Atividade 3: Apresentar para os alunos a proposta de trabalho e sua finalidade. } \\
\text { Objetivo: Estimular a participação dos alunos na proposta apresentada }\end{array}$ \\
\hline $\begin{array}{l}\text { Atividade 4: Sondagem do conhecimento das turmas acerca dos conteúdos } \\
\text { filosóficos } \\
\text { Objetivo: Conhecer o quanto os alunos dominam dos conteúdos filosóficos }\end{array}$ \\
\hline
\end{tabular}




\section{Tabela 1}

Atividades desenvolvidas na inovação (continuação)

\begin{tabular}{|c|c|}
\hline & \\
\hline & $\begin{array}{l}\text { Atividade 5: Planejamento dos colóquios, temas a serem abordados e convidados. } \\
\text { Objetivo: Planejar os colóquios. }\end{array}$ \\
\hline & $\begin{array}{l}\text { Atividade 6: Primeiro Colóquio Filosófico, abordando o tema: } \bigcirc \text { conhecimento } \\
\text { para a filosofia. } \\
\text { Objetivo: Reconhecer que o conhecimento permeia entre os saberes. }\end{array}$ \\
\hline & $\begin{array}{l}\text { Atividade 7: Segundo Colóquio Filosófico, abordando o tema: Filosofia, a } \\
\text { relação entre ética e moral } \\
\text { Objetivo: Ampliar o conceito de ética e moral com os alunos. }\end{array}$ \\
\hline & $\begin{array}{l}\text { jio Filosófico, abordando o tema: Bioética, o que é? } \\
\text { extremamente complexo e atual, ampliando o leque } \\
\text { t. }\end{array}$ \\
\hline & $\begin{array}{l}\text { Atividade 9: Quarto Colóquio Filosófico, abordando o tema: A questão da } \\
\text { ecoética. } \\
\text { Objetivo: Discutir um tema extremamente complexo e atual, ampliando o leque } \\
\text { de conhecimento dos alunos. }\end{array}$ \\
\hline
\end{tabular}

Fonte: Elaboração própria

\section{Estratégias de monitoramento e avaliação}

Embora muitas vezes esta etapa não seja levada em consideração, a etapa do monitoramento é essencial, pois possibilita a coleta de dados de desempenho, bem como, dá um feedback sobre o processo da proposta e seu desenvolvimento, o monitoramento possibilita acompanhar e avaliar a execução da estratégia.

Neste projeto de inovação foram utilizados instrumentos diferentes para o monitoramento como: a lista de frequência, atas das reuniões, participação nos debates e avaliações escrita.

Como instrumentos de inferência do desenvolvimento na implementação do projeto de inovação foram elegidas atas de reuniões com as devidas deliberações (com o coordenador geral e diretor, as coordenações e o professor de Filosofia do colégio); atas da frequência dos alunos nos colóquios, o que foi muito satisfatório, pois os colóquios aconteceram no horário escolar; 
contagem dos que desejavam participar do projeto, tendo uma adesão máxima e a sondagem escrita ao final de cada colóquio, que mostrou ao longo de cada colóquio a satisfação e a importância dada pelos alunos a proposta de cada tema.

Este acompanhamento foi processual e contínuo durante a implementação do projeto de inovação junto a população beneficiada (alunos do $9^{\circ}$ anol, professores convidados, sendo eles: Lucas Dantas, Doutorando em Filosofia pela Universidade Federal de Pernambuco-UFPE; Felipe Xavier, Mestre em Filosofia pela Universidade Católica de Pernambuco-UNICAP; Evandro Costa, Doutorando em Filosofia pela Universidade Federal de PernambucoUFPE e Marcelo Alves Santos, Mestre em Filosofia pela Universidade Federal de Pernambuco-UFPE, para o desenvolvimento dos temas, professores das turmas que os acompanharam nos colóquios e coordenações pedagógicas que apresentaram muita satisfação com o projeto desenvolvido, abrindo assim a ampliação do projeto também para o Ensino Médio em 2018 e implementação da disciplina de Filosofia na grade curricular para os alunos do ano final do Ensino Fundamental em 2019.

Resultados da inovação

Para se enquadrar na complexa dinâmica do mercado atual, é preciso estar sempre interpretando sinais, acompanhando as constantes mudanças e se adaptado a elas. Uma boa análise de dados oferece um grande suporte, pois facilita na tomada de decisões mais precisas e assertivas. Para este fim, foi escolhido como monitoramento da implementação da inovação uma avaliação, buscando identificar como os alunos reagiam ao final de cada colóquio, se os temas abordados eram relevantes para sua aprendizagem, e se a antecipação dos conteúdos era positiva ou não.

Como monitoramento foi realizado uma sondagem inicial com estes alunos que ficou evidente não o desconhecimento total do conteúdo de política quanto a moral e ética, mas que este conhecimento era sem consistência por se tratar do senso comum. Diante deste quadro o projeto foi viabilizado. E durante os temas agora abordados de forma sistemática, também foram aplicados instrumentos como termômetro para um comparativo da sondagem inicial com o conhecimento que se modificava a cada tema abordado. Foram instrumentos 
compostos de duas perguntas acerca da importância dos temas abordados, se os mesmos ajudaram a ampliar os conhecimentos que os alunos já tinham sobre os temas e na melhoria da construção de seus argumentos.

Também foi aplicado com os alunos do $9^{\circ}$ ano do Ensino Fundamental, uma avaliação no final da implementação do projeto, para aferir se o mesmo havia atingido a expectativa inicial de melhoria da compreensão e apreensão de conceitos filosóficos para um bom resultado na disciplina quando estes alunos tiverem seu contado com a filosofia, principalmente no primeiro trimestre, espaço temporal, em que se diagnosticou a maior dificuldade de aprendizagem. Esta avaliação final foi feita a partir da percepção dos alunos, professores acompanhantes, palestrante do último colóquio e coordenação, sobre os aspectos: relevância dos temas, planejamento e organização, palestrantes convidados.

Também foi percebido com o monitoramento que os recursos utilizados nos colóquios como: músicas, trechos de filmes e charges ajudaram bastantes para o desenvolvimento dos temas abordados. Bem como, a estrutura física cedida para os colóquios, o auditório (com ar-condicionado, microfones, data-show, quadro, piloto para quadrol.

Para avaliação do projeto de inovação havia a intenção de analisar os resultados da primeira atividade didática realizada pelo professor de filosofia para os alunos da $1^{a}$ série do Ensino Médio, que durante a implementação eram alunos do $9^{\circ}$ ano do Ensino Fundamental. Esta análise dos primeiros resultados comparadas a sondagem inicial feita com os alunos no dia 17 de agosto de 2017, iria elucidar e validar a eficácia da inovação educativa. Porém pela necessidade de extrapolar o tempo escolar de 2017 para esta avaliação e da necessidade da conclusão do trabalho para defesa do mesmo, foi utilizado uma avaliação a partir da construção coletiva de um mural onde alunos e todos envolvidos direta ou indiretamente (palestrantes convidados, professores acompanhantes, e coordenadores) puderam deixar registrado suas impressões quanto a importância e eficácia do projeto de inovação.

\section{Resultados previstos e alcançados}

Como todo projeto ao ser planejado cria-se uma expectativa em relação aos resultados idealizados, os resultados esperados com os resultados 
alcançados. Para melhor compreensão trataremos dos resultados previstos como sendo aqueles que dão resposta, estão relacionados com os objetivos específicos.

Alguns aspectos podem ser destacados durante a implementação do projeto de inovação a partir dos quatro colóquios vivenciados. Sendo eles:

a) A frequência dos alunos nos colóquios, foram observados através das atas de frequência. Comparecendo no $1^{\circ}$ colóquio 49 alunos participaram; no $2^{\circ}$ e $3^{\circ}$ colóquios 52 alunos participaram e no $4^{\circ}$ colóquio todos alunos participaram quantificando 53 alunos. Foi observado um crescimento na presença a medida que os colóquios iam acontecendo.

b) Que os alunos apresentaram uma boa disposição para participar dos colóquios desde a apresentação do projeto, quando todos os alunos disseram que gostariam de participar dos colóquios, como proposta de aquisição de conhecimento e levaram para o pais a carta/comunicado sobre o evento.

c) E se envolverem nas discussões propostas em cada colóquio. Apesar da estranheza do que iria acontecer no primeiro colóquio, nos poste12 riores, já apresentavam alegria em participar. Como falam os 5 alunos que aceitaram participar, mas faziam ideia do que iria acontecer, mas que gostaram bastante e os 20 alunos disseram estarem felizes por fazerem parte destes colóquios, pois estão ensinando muitas coisas.

a) Os temas filosóficos selecionados como significativos que atenderam às expectativas iniciais de despertar nos alunos o interesse pela discussão e questionamentos. Dando resposta para a capacidade de apreensão de conteúdos sistemáticos da grade curricular do Ensino Médio, de forma prazerosa e eficaz para os alunos do $9^{\circ}$ ano do Ensino Fundamental. Onde 32 alunos externaram que os temas abordados já eram de conhecimento deles, mas que só tinha o conhecimento do senso comum, não sabendo que tinha uma disciplina que tratassem destes conteúdos.

b) A percepção por parte dos alunos da possibilidade de tratar um mesmo tema a partir de vários saberes ajudando-os a refletir na tomada de decisão em algumas situações problemas que thes foram apresentadas para resolução. Onde 15 alunos disseram que estava saindo dos colóquios com mais conhecimento para colocar em prática em seus cotidianos 
c) A tomada de decisão frente a situações problemas que foram apresentados a eles pelo último palestrante convidado que os fez lançar mão de vários conceitos e saberes e dentre eles o saber filosófico de refletir sobre o pensado e colocado, sem partir exclusivamente do senso comum. Levando em consideração os princípios e valores éticos e morais.

d) Na avaliação do projeto de inovação, os alunos avaliaram positivamente a experiência das colóquias porque 47 dos 53 alunos ou escreveram que os colóquios contribuiram para seu crescimento intelectual e ajudaram a refletir sobres os temas abordados.

\section{Discussão dos resultados}

Com o propósito de contribuir na melhoria da aprendizagem na disciplina de filosofia para os alunos das séries iniciais do Ensino Médio, o projeto buscou antecipar alguns conteúdos pré-requisito para os alunos do $9^{\circ}$ do Ensino Fundamental, através de Colóquios Filosóficos, usando de uma metodologia mais prazerosa.

\section{Tabela 2}

\section{Comparação por dimensão entre o marco-teórico conceitual e os resultados}

\begin{tabular}{|c|c|c|}
\hline \multicolumn{3}{|c|}{$\begin{array}{c}\text { Comparação por dimensão entre o marco- teórico conceitual } \\
\text { e os resultados obtidos na inovação educativa }\end{array}$} \\
\hline Dimensão & $\begin{array}{l}\text { Visão do marco teórico } \\
\text { e conceitual }\end{array}$ & Resultado da intervenção educativa \\
\hline \multirow{3}{*}{ 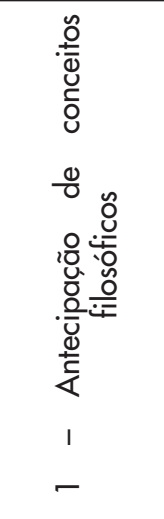 } & $\begin{array}{l}\text { "preveem a adoção de temas } \\
\text { transversais nesse nível de ensino, } \\
\text { notadamente nas áreas de ética } \\
\text { e cidadania". (PCNEF, 1998). }\end{array}$ & $\begin{array}{l}\text { O desenho do projeto de inovação } \\
\text { através dos colóquios antecipando o } \\
\text { conteúdo de política, contribuiu para } \\
\text { apropriação de alguns conceitos diluindo- } \\
\text { os e tornando-os mais compreensivos. }\end{array}$ \\
\hline & \multirow{2}{*}{$\begin{array}{l}\text { "Crítias testemunha que a } \\
\text { infância é, para os gregos, um } \\
\text { período extraordinário para o } \\
\text { aprendizado: "é comum dizer } \\
\text { que o que se aprende sendo } \\
\text { criança fica de modo admirável } \\
\text { na memória"." (Kohan, 2008). }\end{array}$} & $\begin{array}{l}\text { Como falam } 5 \text { alunos: que aceitaram } \\
\text { participar, que não faziam ideia do que iria } \\
\text { acontecer, mas que gostaram bastante. }\end{array}$ \\
\hline & & $\begin{array}{l}\text { Outros } 32 \text { alunos externaram que os } \\
\text { temas abordados já eram de conhecimento } \\
\text { deles, mas que só tinha o conhecimento do } \\
\text { senso comum, não sabendo que tinha uma } \\
\text { disciplina que tratassem destes conteúdos }\end{array}$ \\
\hline
\end{tabular}




\section{Tabela 2}

\section{Comparação por dimensão entre o marco-teórico con-} ceitual e os resultados (continuação)

\begin{tabular}{|c|c|c|}
\hline \multicolumn{3}{|c|}{$\begin{array}{c}\text { Comparação por dimensão entre o marco- teórico conceitual } \\
\text { e os resultados obtidos na inovação educativa }\end{array}$} \\
\hline Dimensão & $\begin{array}{l}\text { Visão do marco teórico } \\
\text { e conceitual }\end{array}$ & Resultado da intervenção educativa \\
\hline \multirow{2}{*}{ 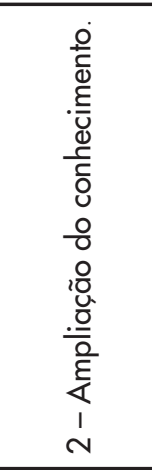 } & \multirow{2}{*}{$\begin{array}{l}\text { "o estudo da filosofia, enriquece } \\
\text { a imaginação intelectual da } \\
\text { pessoa e faz diminuir a arrogância } \\
\text { dogmática. Sobretudo, porque } \\
\text { engrandece o espírito, tornando-o } \\
\text { capaz de perceber a multiplicidade } \\
\text { de pontos de vista e articulações } \\
\text { possíveis entre os mesmos, } \\
\text { ajudando-o a compreender que o } \\
\text { caminho é um processo, mas que } \\
\text { pode ser para cima e para frente". } \\
\text { (Esquisani, 2001) }\end{array}$} & $\begin{array}{l}\text { Os colóquios possibilitaram } \\
\text { desenvolver a capacidade de atuação } \\
\text { crítica frente aos desafios impostos } \\
\text { pelo contexto sociocultural. }\end{array}$ \\
\hline & & $\begin{array}{l}\text { Onde } 20 \text { alunos disseram estarem } \\
\text { felizes por fazerem parte destes } \\
\text { colóquios, pois estão ensinando muitas } \\
\text { coisas. }\end{array}$ \\
\hline \multirow{3}{*}{ 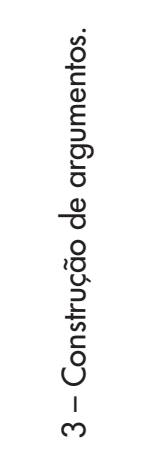 } & \multirow{3}{*}{$\begin{array}{l}\text { "dominar os conhecimentos de } \\
\text { filosofia e de sociologia necessários } \\
\text { ao exercício da cidadania". (LDB } \\
9.394 / 96 \text {, no artigo 36) }\end{array}$} & $\begin{array}{l}\text { Os colóquios oportunizaram momentos } \\
\text { de troca de experiências, debates e } \\
\text { tomada de decisão. }\end{array}$ \\
\hline & & $\begin{array}{l}\text { Onde } 15 \text { alunos disseram que estava } \\
\text { saindo dos colóquios com mais } \\
\text { conhecimento para colocar em prática } \\
\text { em seus cotidianos. }\end{array}$ \\
\hline & & $\begin{array}{l}\text { Onde } 47 \text { dos } 53 \text { alunos ou escreveram } \\
\text { que os colóquios contribuiram para } \\
\text { seu crescimento intelectual e ajudaram } \\
\text { a refletir sobres os temas abordados. }\end{array}$ \\
\hline
\end{tabular}

Fonte: Elaboração própria

Em síntese, podemos dizer que o projeto de inovação buscando antecipar o conteúdo de política para os alunos do $9^{\circ}$ ano, objetivando ampliar seus conhecimentos e construção de argumentos para sua formação intelectual e atitudinal atingiram as expectativas com base nos relatos dos alunos a partir dos monitoramentos em cada colóquio e da avaliação da inovação. E que estão correlacionados com a fundamentação teórica levantada neste projeto.

Quanto a implementação do projeto, tomando como base os objetivos específicos que foram elencados, percebe-se que foram atingidos 
satisfatoriamente desde a escolha do conteúdo a ser trabalhado, partindo da observação e levantamento do plano anual da disciplina na $1^{a}$ série do Ensino Médio - com a avaliação positiva de quase todos os alunos quanto aos temas abordados (considerando que a contagem deste aspecto aconteceu a cada tema trabalhado); do planejamento da proposta de inovação que possibilitou um caminho a ser seguido sem perder o foco do trabalho - avaliado por 47 alunos, como muito bem planejado e organizado, dentro do horário previsto; a execução do projeto de inovação que foi a parte mais prazerosa a ser desenvolvida, onde se percebeu a realização de tudo que foi planejado - em que 53 alunos avaliaram positivamente, a proposta de quatro palestrantes diferentes para trazer a discussão dos temas e complementando o conhecimento trabalhado nos colóquios anteriores; e a avaliação da inovação - em que 47 alunos consideraram positiva a experiência dos Colóquios Filosóficos, pois contribuíram para ampliar seu leque de conhecimento acerca de temas filosóficos e a percepção da possibilidade de tratar um mesmo tema a partir de vários saberes.

Com base nos objetivos específicos escolhidos foi feito análise dos resultados alcançados:

a) Com o segundo e quarto objetivo, intencionou-se proporcionar a antecipação de conceitos pré-requisitos para o estudo da disciplina de filosofia, ampliando assim o campo de conhecimento dos alunos e que estes conceitos fossem significativos para sua aprendizagem. Nestes aspectos, usando os dados levantados durante o monitoramento, ficou claro que os alunos avaliaram como positiva esta antecipação.

b) Quanto ao terceiro objetivo, buscou-se implementar os Colóquios Filosóficos para a apropriação dos princípios e valores éticos e moral que fazem parte da grade curricular das séries iniciais do Ensino Médio, possibilitando assim que quando estiverem na série posterior, consigam compreender e apreender melhor os conteúdos trabalhados e obter bons resultados nas primeiras atividades avaliativas, que são a maiores dificuldades dos alunos. Esta implementação foi positiva e exitosa, pois aconteceu sem maiores dificuldades, com o apoio da equipe diretiva e com as contribuições dos palestrantes convidados.

c) Com o quinto objetivo, buscou-se avaliar o projeto de inovação que aconteceu no último colóquio, com a construção de um mural, onde os 
alunos participantes da inovação puderam escrever quais as suas impressões a respeito do projeto no qual fizeram parte. Como resultado os alunos avaliaram positivamente a experiência das colóquias porque 47 dos 53 alunos, escreveram que os colóquios contribuiram para seu crescimento intelectual e ajudaram a refletir sobres os temas abordados ampliando seu leque de conhecimentos a cerca de temas filosóficos. Ainda 39 dos 53 alunos questionaram o porque da disciplina de filosofia não fazer parte da grade curricular deles, já que traz a posibilidade de reflexão necessária para os dias atuais.

Observando a discussão dos resultados, seja através da tabela Comparação por dimensão entre o marco- teórico conceitual e os resultados obtidos na inovação educativa e da expressão escrita dos alunos coletadas desde o monitoramento da implementação até a avaliação da inovação, pode-se perceber que o projeto Colóquios Filosóficos correspondeu aos seus objetivos, surgindo como um projeto de êxito, criando a possibilidade de sua realização no ano de 2018 com alguns ajustes necessário diante da nova proposta apresentada. Estes ajustes vão desde a população beneficiada que se estenderá para todo Ensino Médio, os temas abordados, a possibilidade do cruzamento de outras disciplinas como: História, Geografia, Ensino Religioso 16 e Sociologia.

\section{Conclusão}

A partir da análise dos dados coletados no início da investigação da aprendizagem na disciplina, nos anos de 2015, 2016 e 2017 foi identificado que esta disciplina consta no rol de disciplinas que os alunos têm dificuldades, juntamente com as disciplinas de Língua Portuguesa e Matemática, que a maior dificuldade se apresenta na $1^{a}$ série do Ensino Médio e mais fortemente no primeiro trimestre. $\bigcirc$ que demostrou que o contato com a nova disciplina causa com seu arcabouço denso de conteúdos e didática de trabalho própria, uma dificuldade na compreensão e apreensão da aprendizagem.

Diante do quadro desenhado acima, este projeto de inovação buscou proporcionar a melhoria da compreensão e apreensão da aprendizagem de conceitos filosóficos relacionados a política, que é conteúdo da grade curricular da $1^{a}$ série do Ensino Médio, no primeiro trimestre escolar. 
Com o desafio de sanar a dificuldade encontrada foi elaborado o projeto: Colóquios Filosóficos para os alunos do $9^{\circ}$ ano do Ensino Fundamental, antecipando dos conceitos pré-requisitos da disciplina de filosofia para o ano posterior. Sabendo que, o ensino desta disciplina só está regulamentado na Lei de Diretrizes e Bases 9.394/96, aprovada em 20 de dezembro de 1996 para o Ensino Médio, no entanto, no PCNEF, publicado em 1998, está previsto o trabalho com temas transversais sobre a ética e a moral.

A decisão da estratégia didática por meio de colóquios se fundamentou a partir da proposta de trabalho que este modelo apresenta, possibilitando uma metodologia de exposição de conceitos, troca de experiências, discussões e tomada de posicionamento. Características própria de um saber filosófico que não buscar apenas conhecer os conceitos das coisas e diferenciá-los dos demais, mas aprofundar neste conceito buscando saber o porquê, de onde surgiu, sua empregabilidade e funcionalidade.

Quanto ao colégio (na pessoa das coordenações do Ensino Fundamental e Médio), o projeto foi avaliado como uma possibilidade a mais de desenvolver a capacidade de elaboração de argumentos e posicionamentos diante de situações que exigem deles uma tomada de decisão. E principalmente, levantou-se a necessidade de trabalhar os Colóquios filosóficos com todas as séries do Ensino Médio.

Por fim, digo que: a) a Lei de Diretrizes e Bases 9.394/96, de 20 de dezembro de 1996, foi importante para chamar a atenção da importância do ensino de filosofia, porém os problemas continuam, e só serão resolvidos quando os professores e os legisladores se empenharem em efetivar a filosofia em todos os níveis dando condições estruturais para que os professores tenham a árdua tarefa de ensinar os alunos a pensar filosoficamente; b) A filosofia é importante para o desenvolvimento de uma sociedade melhor onde predomine o diálogo, a discussão filosófica, numa reflexão sobre comportamentos morais e éticos com parâmetros em nossas ações e vivências sem autoritarismos, com liberdade e autonomia; e c) $\bigcirc$ ensino de filosofia é fundamental para a consolidação da democracia, para a discussão de temas pertinentes e para o desenvolvimento do pensamento social e políico da nossa sociedade.

Sendo assim, a filosofia é de vital importância para a educação em todos os seus níveis de ensino. Ela obedece a um esforço no sentido 
de questionar, debater os problemas referentes à existência humana, isto é, desenvolver um espírito crítico, suscitando a liberdade para o exercício da democracia.

\section{Notas}

1 FODA é uma ferramenta de planejamento estratégico na gestão de projetos, usada para analisar cenários, embasar a tomada de decisões e está dividida em quatro grandes óticas: Fortalezas, Oportunidades, Debilidades e Ameaças. Também conhecida como Matriz SWOT, Análise FOFA ou ainda Matriz FOFA.

\section{Referências}

BRASIL. Secretaria de Educação Fundamental. Parâmetros Curriculares Nacionais: terceiro e quarto ciclos: apresentação dos temas transversais/ Secretaria de Educação Fundamental. Brasília: MEC/SEF, 1998.

BRASIL, Ministério da Educação. Secretaria de Educação Média e Tecnológica. Parâmetros 18 Curriculares Nacionais: ensino médio. Ciências Humanas e suas Tecnologias. Brasília: MEC/SEMTEC, 2000. (v. IV).

BRASIL. Lei n 9.394, de 20 de dezembro de 1996. Estabelece as Diretrizes e Bases da Educação Nacional. Diário Oficial União, Poder Executivo, Brasília, DF, 23 de dezembro de 1996. Seção 1, p. 27833.

CIRINO, Maria Reilta Dantas. Filosofia com criança: estratégia para o pensar bem infantil. In: MATOS, Junot Cornélio; COSTA, Marcos Roberto Nunes. Ensino de filosofia: questões fundamentais. Recife: Editora UFPE, 2014

ESQUISANI, Valdecir Antônio. Mundo jovem - Um jornal de ideias. Ensinar a pensar. Porto Alegre: Editora da PUCRS, 2001.

FLECHSIG, KARL-HEINZ; SCHIEFELBEIN, ERNESTO. Vinte modelos didáticos para América Latina. Washington: Series Colección Interamer, 2003. (v.VI).

GAMBIM, Pedro. Mundo jovem - um jornal de ideias. $\bigcirc$ que é filosofia? Porto Alegre: Editora da PUCRS, 2000.

LIMA, Caroliny Santos. Crianças filosofando: uma proposta metodológica de ensino à luz de Mattheuw Lipman. São Luís: Editora UFMA, 2018. 
LORIERI, Marcos Antônio. Filosofar com criança: possibilidades. Contribuições de Matthew Lipman. In: Matos, Junot Cornélio; Costa, Marcos Roberto Nunes. Ensino de filosofia: questões fundamentais. Recife: Editora UFPE, 2014.

KOHAN, Walter Omar. Filosofia para crianças na prática escolar. Petrópolis: Vozes, 1998. $\mathrm{KOHAN}$, Walter Omar. Filosofia para crianças. Rio de Janeiro: Lamparina, 2008.

SILVA, Gilson da. O ensino de filosofia nas perspectivas inter e transdisciplinar: uma análise da problemática ontológica. Revista Educação em Questão, Natal, v. 57, n. 51 . p. 1-30, jan./mar. 2019.

Ana Cristina Aureliano Universidad de Santiago de Chile (Chile) Facultad de Humanidades Departamento de Educación Orcid id: https: / / orcid.org/0000-0003-28 1 0-8569 E-mail: ana.aureliano@salesianorecife.com.br Recebido 8 abr. 2020 Aceito 19 maio 2020 